\title{
Modern Immunosuppressive Therapy in Kidney Transplantation
}

\author{
Rubin Zhang \\ Section of Nephrology and Hypertension, Department of Medicine, Tulane University School of Medicine, \\ New Orleans, Louisiana, USA \\ Email: rzhang@tulane.edu
}

Received March 28, 2013; revised April 30, 2013; accepted May 10, 2013

Copyright (c) 2013 Rubin Zhang. This is an open access article distributed under the Creative Commons Attribution License, which permits unrestricted use, distribution, and reproduction in any medium, provided the original work is properly cited.

\begin{abstract}
Immunosuppressive therapy is a key component for successful kidney transplantation. It is commonly believed that more intensive immunosuppression is needed initially to prevent rejection episodes and less immunosuppression is subsequently maintained to minimize the overall risk of infection and malignancy. The selection of drugs should be guided by a comprehensive assessment of the immunologic risk, patient comorbidities, financial cost, drug efficacy and adverse effects. Lymphocyte-depleting antibody induction is recommended for patients with high immunologic risk, while IL-2R antibody can be used for low or moderate risk patients. Patients with very low risk may be induced with intravenous steroids without using an antibody. A maintenance regimen typically consists of a low-dose of steroid combined with two of the four class drugs: calcineurin inhibitor (tacrolimus or cyclosporine), antimetabolite (mycophenolate mofetil or enteric coated mycophenolate sodium), mTOR inhibitor (sirolimus or everolimus) and costimulation blocker (belatacept). Currently in the USA, the most popular maintenance is the combination of corticosteroid, mycophenolic acid and tacrolimus. Steroid minimization, or calcineurin inhibitor free or withdrawal should be limited to the highly selected patients with low immunological risk. Recently, the novel biological agent belatacept-based maintenance has demonstrated a significantly better renal function and improved cardiovascular and metabolic profile, which may provide hope for an ultimate survival benefit.
\end{abstract}

Keywords: Kidney Transplantation; Immunosuppression; Antibody Induction; Maintenance Therapy; Acute Rejection

\section{Introduction}

The discovery and clinical application of potent immunosuppressive agents have successfully reduced the risk of acute rejection and graft loss from rejection. Kidney transplant has become the preferred therapy for treating patient with ESRD. Modern immunosuppressive protocol typically includes an induction therapy and a long-term maintenance. Antibody induction is recommended in patients with immunologic risk, but the choice of antibody remains controversial. In the USA, about $60 \%$ of kidney transplant patients in the year of 2011 were given a T-cell depleting antibody induction, predominately the antithymocyte globulin (ATG). Other $40 \%$ of patients received either IL-2 receptor antibody (IL-2R Ab) or no antibody induction [1]. Maintenance immunosuppression is required for the lifetime of functioning allograft to prevent rejection of transplanted kidney. It is generally accepted that more intensive immunosuppression is given initially and less immunosuppression is subsequently maintained to minimize the overall risk of infection and malignancy. A maintenance regimen typically consists of two of the four classes of drugs with a low-dose of glucocorticoids: 1) calcineurin inhibitor (tacrolimus or cyclosporine); 2) antimetabolite (mycophenolate mofetil or enteric coated mycophenolate sodium); 3) mTOR inhibitor (sirolimus or everolimus); and 4) costimulation blocker (belatacept). In the USA, the most popular maintenance either at beginning of transplant or at 1 year after transplant remains the combination of corticosteroid, mycophenolic acid (MFA) and tacrolimus [1].

\section{Induction Antibody Preparations}

\subsection{OKT-3}

OKT-3 is a murine monoclonal antibody against CD3 molecule. It binds to the T-cell receptor-associated CD3 glycoprotein, leading to initial activation and cytokine release, followed by blockade of function and T-cell depletion. It is associated with severe side effects, and ATG 
preparation was demonstrated to be superior than OKT-3 in decreasing the incidence of rejection and better tolerability [2-5]. The use of OKT-3 was subsequently decreased and led to cessation of its production in 2009.

\subsection{Antithymocyte Globulin (ATG)}

There are two forms of ATG that are polyclonal immunoglobulins from horses (ATGAM) or rabbits (thymoglobulin) immunized with human thymocytes. ATG binds to various cell surface markers, leads to complement dependent lysis of lymphocytes. OKT-3, ATGAM, thymoglobulin and alemtuzmab are often referred as lymphocyte-depleting antibodies, which are usually used in patients who have high immunological risk of rejection [2]. ATG use is associated with cytokine release syndrome, myelosuppression and rarely anaphylactic reaction. Several studies found that thymoglobulin was more effective in preventing rejection and was associated with better graft survival than ATGAM [6-8]. The dose of thymoglobulin induction has ranged from 1 to 4 $\mathrm{mg} / \mathrm{kg} /$ day for 3 to10 days. Intraoperative administration of thymoglobulin was found to be associated with a lower incidence of delayed graft function (DGF) and shorter hospital stay [9]. Doses less than $3 \mathrm{mg} / \mathrm{kg}$ may not effectively prevent acute rejection (AR). Higher dose and longer duration of induction was associated with increased risk of infection and lymphoma. Therefore, the optimal dose of thymoglobulin induction might be a total of $6 \mathrm{mg} / \mathrm{kg}$ administered as $1.5 \mathrm{mg} / \mathrm{kg} /$ day in 3 to 5 days $[10,11]$.

\subsection{IL-2 Receptor Antibody (IL-2R Ab)}

Daclizumab and basiliximab are the two IL-2R Abs. Daclizumab is a humanized antibody and basiliximab is a chimeric monoclonal antibody. Both bind to the alpha chain of IL-2 receptor (CD25) expressed on activated T lymphocytes. They prevent $\mathrm{T}$ cell proliferation without causing cell lysis and have minimal adverse effects. IL2R Abs are also known as non-depleting antibodies, and frequently used in patients who have a low-to-moderate risk of rejection [12-15]. Basiliximab is administered as 2 doses within 4 day of transplantation, whereas daclizumab is administered as 5 doses over 8 weeks. This difference in convenience of administration led to more frequent use of basiliximab than daclizumab. Subsequently, Roche pharmaceuticals withdrew daclizumab from market in October 2008.

\subsection{Alemtuzumab}

Alemtuzumab is a humanized anti-CD52 monoclonal antibody, which triggers antibody-dependent lysis of lymphocytes (both B and T cells), NK cells, and, to a lesser extent, of monocytes and macrophages. Alemtuzumab is FDA approved for treating B cell lymphomas. As an induction agent, it produces a profound depletion of lymphocytes and is associated with more frequent and severe adverse effects, such as neutropenia, thrombocytopenia, thyroid disease, autoimmune hemolytic anemia and other autoimmune diseases [16-18]. It is hoped that alemtuzumab induction could permit patients to be maintained on unconventional strategy with less intensive immunosuppression, such as tacrolimus monotherapy [19], steroid-free [20], steroid and calcineurin inhibitor (CNI) free regimen [21].

\subsection{Rituximab}

Rituximab is a chimeric monoclonal Ab against CD20, which is expressed on the majority of B cells. It was first approved in 1997 for refractory B cell lymphomas and it is increasingly applied for autoimmune diseases. In the realm of kidney transplant, rituximab has been used in combination with plasmapheresis and IVIG to treat antibody-mediated rejection (AMR), and to desensitize patients with preformed antibodies for ABO- and/or HLAincompatible kidney transplant [22,23].

\section{Considerations in Choosing Antibody Induction Therapy}

Antibody selection should be guided by a comprehensive assessment of immunologic risk, patient comorbidities, financial burden, and the maintenance immunosuppressive regimen. Clinical trials comparing different antibody induction in various patient populations and with different maintenance immunosuppression are recently reviewed by the author [2]. The published data remain in line with the 2009 KDIGO guideline [24]. Lymphocytedepleting antibody is recommended for those with high immunologic risk as outlined in the 2009 KDIGO clinical practice guidelines (sensitized patient, presence of donor specific antibody, ABO incompatibility, high HLA mismatches, DGF, cold ischemia time $>24$ hours, African-American ethnicity, younger recipient age, older donor age), though it increases the risk of infection and malignancy [24]. For low or moderate risk patients, IL$2 \mathrm{R} \mathrm{Ab}$ induction reduces the incidence of acute rejection and graft loss without much adverse effects, making its balance favorable in these patients [25-27]. IL-2R Ab induction should also be used in the high risk patients with other comorbidities (history of malignancy, viral infection with HIV, HBV or HCV, hematological disorder of leucopenia or thrombocytopenia and elderly) that may preclude usage of lymphocyte-depleting antibody safely [28-30]. Many patients with very low risk (nonsensitized, Caucasian, Asian, well HLA matched, living related donor transplant) may be induced with intrave- 
nous steroids without using any antibody, as long as combined potent immunosuppressives are kept as maintenance. In these patients, benefits with antibody induction may be too small to outweigh its adverse effects and the financial cost $[2,24,31]$. Clinical comparison trials have not demonstrated any graft or patient survival benefit of using T-cell depleting Ab induction in patients with low immunological risk [2,24]. Rituximab induction is useful in desensitization protocols for ABO and/or HLA incompatible transplants. Alemtuzumab induction might be more successful for adopting less intensive maintenance protocols. However, the long-term safety and efficacy of unconventional strategy remain to be determined.

\section{Maintenance Immunosuppressive Drugs}

\subsection{Glucocorticoids}

Glucocorticoids have been used for preventing and treating graft rejection since the early 1960s. They have multiple actions. In addition to the nonspecific anti-inflamematory actions, glucocorticoids have critical immunosuppressive effect by blocking T-cell and antigen-presenting cell (APC) derived cytokine expression. Glucocorticoids bind to cytoplasmic receptor to form a complex, which translocates into the nucleus and binds to glucocorticoid response elements (GRE) in the promoter regions of cytokine genes. Glucocorticoids also inhibit the translocation of transcription factor AP-1 and NF- $\kappa \mathrm{B}$ into the nucleus. Therefore, production of several cytokines (IL-1, 2, 3, 6, TNF- $\alpha$, gamma-interferon) are inhibited $[32,33]$. Large dose of glucocorticoids can be given in the perioperative period as induction therapy (methylprednisolone 250 to $500 \mathrm{mg}$ IV), which is usually followed by oral prednisone 30 to $60 \mathrm{mg} /$ day. The dose is tapered over 1 to 3 months to a typical maintenance dose of 5 to $10 \mathrm{mg} /$ day. Side effects are well known, including weight gain, cataract, bone loss, fracture, avascular necrosis, glucose intolerance, hyperlipidemia, and hypertension [34,35].

\subsection{Calcineurin Inhibitors (CNIs)}

The introduction of cyclosporine into clinical usage in 1978 revolutionized solid organ transplant arena. It significantly decreased the incidence of acute rejection and improved early graft survival [36-39]. Cyclosporine is an 11-amino-acid cyclic peptide from Tolypocladium inflatum. It binds to intracellular cyclophilin to form a complex. This complex inhibits calcineurin phosphatase, blocks migration of NFAT from the cytoplasma into nucleus, therefore, inhibits cytokine (IL-2, IL-4, etc.) production [32,33]. Microemulsion formulation (Neoral) is miscible in water and has better oral bioavailability than original preparation $[37,38]$. Side effects of cyclosporine include acute and chronic nephrotoxicity, electrolyte dis- orders (hyperkalemia, hypomagnesemia, hyperuricemia), thrombotic microangiopathy (TMA), hypertension, neurotoxicity (tremor, dysesthesias, insomnia, headache), gingival hyperplasia, hypertrichosis, hirsutism, new onset diabetes after transplant (NODAT), hyperlipidemia, and bone pain syndrome. Clinical monitoring of trough level or peak level two hours after administration is required to adjust cyclosporine dosage [40]. Tacrolimus (FK506) was approved by FDA in 1994 for liver transplant and in 1997 for kidney transplant. It is a macrolide antibiotic from Streptomyces tsukubaensis. It binds to FK506binding protein (FKBP) to form a complex that inhibits calcineurin phosphatase with greater potency than cyclosporine. The use of tacrolimus has increased steadily, and it is now the dominant CNI, as it is associated with lower incidence of rejection [41-45]. Side effects are similar to cyclosporine in that it can cause acute and chronic nephrotoxicity, TMA and electrolyte problems. But tacrolimus has a lower incidence of hypertension, hyperlipidemia, cosmetic skin changes, and gum hyperplasia and a higher incidence of neurotoxicity and NODAT. The risk factor for NODAT includes African American ethnicity, older age, HCV infection and obesity. Hirsutism is uncommon, but hair loss and even alopecia are associated with tacrolimus usage. Trough level monitoring is required to adjust its dosage. There is a new preparation of modified-release tacrolimus to permit once-daily dosing [46]. Both CNIs are metabolized by the cytochrome P-450 CYP3A4 enzyme. Any drug or nutrition supplement that induces or inhibits this enzyme may increase or decrease CNI level and need to adjust CNI dose respectively. Such common drug-drug interacttions are summarized in Table $\mathbf{1 .}$

\subsection{Antimetabolites}

There are several antimetabolites available. Azathioprine has been used as an immunosuppressive agent since early 1960s [47-49]. It is a prodrug of 6-mercaptopurine, which interferes with DNA synthesis by inhibiting metalloproteinase and synthesis of thioguanine nucleotides. It is metabolized by xanthine oxidase. Therefore, concurrent use of allopurinol, febuxostat or any other xanthine oxidase inhibitor should be avoided as it can cause severe leucopenia. The usual maintenance dose is 2 $\mathrm{mg} / \mathrm{kg} /$ day. Common side effects include bone marrow depression, leukopenia, macrocytosis, pancreatitis and liver toxicity. Mycophenolic acid (MFA) is from penicillium molds. It inhibits inosine monophosphate dehydrogenase, therefore, blocks the synthesis of guanosine monophosphate nucleotides and prevents the proliferation of T- and B-cells [32,48]. Mycophenolate mofetil (MMF) is a prodrug that requires hydrolysis of the mofetil ester in acid environment to releases MFA [50-53]. Thus, proton-pump inhibitor may reduce the exposure of MMF. 
Table 1. Drugs that affect cytochrome P-450 enzyme and CNI metabolism.

Induction of P-450 and reduction of CNI level

1) Anticonvulsants: barbiturates, phenytoin, carbamazepine, and primidone

2) Antimycobacterial drugs: rifampin, rifabutin, rifapentine, and isoniazid

3) Herbal supplement: St. John's wort

Inhibition of P-450 and increase of CNI level

1) Calcium channel blockers: verapamil, diltiazem, nicardipine, and amlodipine

2) Antiarrhythmics: amiodarone, dronedarone, quinidine and lidocaine

3) Antifungal drugs: ketoconazole, itraconazole, clotrimazole, voriconazole, fluconazole, miconazole, and posaconazole

4) Antibacterial agents: erythromycin, clarithromycin, telithromycin, and synercid

5) Protease inhibitors: amprenavir, atazanavir, boceprevir, darunavir, delavirdine, fosamprenavir, ritonavir, indinavir, saquinavir, tipranavir, telaprevir, and nelfinavir

6) Antidepressant: fluvoxamine

7) Diet supplement: grapefruit juice

Enteric-coated MFA is an active compound and its absorption is not affected by proton-pump inhibitor [54-57]. The typical dose is $1000 \mathrm{mg}$ of MMF or $720 \mathrm{mg}$ of enteric-coated MFA twice daily when used in combination of cyclosporine, and cyclosporine can inhibit their absorption by $30 \%$ to $50 \%$. When used with tacrolimus, reduced dose of MMF or MFA may be also effective as tacrolimus does not reduce their absorption. MFA is superior to azathioprine in preventing acute rejection after kidney transplant $[52,53]$. The combination of MFA and CNI has reduced graft rejection and improved graft survival. MFA has largely replaced azathioprine and is widely used in maintenance protocols [50-57]. The side effects include gastrointestinal symptoms and bone marrow suppression. The enteric-coated MFA is better tolerated due to less gastrointestinal symptoms [56-58]. MFA level can be measured as clinical monitoring, but it is usually unnecessary. MFA should be stopped 6 weeks before conception, as it increases the risk of fetal loss in the first trimester as well as fetus congenital malformations (cleft lip and palate, anomalies of external ear, distal limbs, heart, esophagus and kidney). Leflunomide is a synthetic isoxazole derivative and it inhibits pyrimidine synthesis by inhibiting dihydroorotate dehydrogenase. It is approved for rheumatoid arthritis, and it is sometimes used in transplant patients for BK virus nephropathy. However, its efficacy against BK virus remains controversial $[59,60]$. Side effects include anemia, GI toxicity and elevated liver enzymes.

\subsection{Mammalian Target-of-Rapamycin (mTOR) Inhibitors}

Sirolimus (rapamycin) was approved by FDA in 1999 for prophylaxis of rejection in kidney transplant. It is a macrolide antibiotic derived from $S$. hygroscopicus. It binds to FKBP to form a complex, which inhibits mTOR. Inhibition of mTOR blocks the T-cell proliferation driven by IL-2 [61-63]. Everolimus is a derivative of sirolimus [64]. Both of them are metabolized by cytochrome P-450 CYP3A4. Therefore, they are subject to the similar drug-drug interaction as CNI in Table 1. The adverse effects of mTOR inhibitors include hyperlipidemia, leucopenia, thrombocytopenia, podocyte injury, proteinuria, focal and segmental glomerulosclerosis, delayed recovery of ATN, delayed wound healing, lymphocele formation, oral ulcers, pneumonitis, pleural effusion and ascites. The combination of mTOR inhibitor and CNI may increase the nephrotoxicity, TMA and hypertension $[62,63,65]$. However, mTOR inhibitors may have antineoplastic and antiviral benefits and their usages are associated with lower incidence of malignancy and viral diseases (CMV and BKV infection) [61-65].

\subsection{Belatacept}

Belatacept is the first costimulatory pathway blockage approved as a maintenance immunosuppressive agent for kidney transplant. Belatacept is a fusion protein combining CTLA-4 with the Fc portion of IgG. It blocks the costimulatory pathway CD28-CD80/86 (signal 2) by binding to CD80/86 on T-cells, therefore, inhibits T-cell activation [66]. In the clinical trials with basiliximab induction and MFA and glucocorticoid maintenance, belatacept group provides significantly better kidney function than cyclosporine control despite of higher incidence of acute rejection in the first year [66]. It is also associated with less chronic allograft nephropathy and better 
cardiovascular and metabolic profiles. Betatacept is given intravenously once monthly after the more frequent administration for the initial 2 months. The significant side effect is the increased risk of posttransplant lymphoproliferative disease (PTLD) primarily involving the CNS in patients without Epstein-Barr virus (EBV) immunity. Therefore, belatacept is contraindicated in patients who are EBV seronegative or with unknown EBV serostatus before transplant. Other risk factors for PTLD may include CMV infection and over immunosuppression [66-69].

\section{Other Clinically Used Agents}

\subsection{IVIG}

IVIG is prepared from pooled donor plasma. It contains more than $90 \%$ of intact IgG that can neutralize auto- and allo-antibodies. It blocks Fc receptor on effector cells, inhibits inflammatory cytokines and attenuates complement mediated injury. IVIG may also have a long-term immune modulate effect through inhibiting lymphocyte proliferation and antibody production [70]. IVIG is frequently used in treating AMR as well as in desensitization protocol for $\mathrm{ABO}$ and/or HLA incompatible transplants [71-73]. Commonly side effects include fever, chills, headache, chest tightness, sweating and nausea. Occasionally, the IVIG forms containing high sucrose (such as sandoglobulin) can cause thrombotic event and AKI from sucrose nephropathy.

\subsection{Bortezomib}

Bortezomib is a tripeptide that inhibits $26 \mathrm{~S}$ proteasome. It prevents the degradation of pro-apoptotic factors and activates programmed cell death in immortal neoplastic cells, especially the plasma cells. Bortezomab is approved for the treatment of myeloma. It may be useful in desensitizing the patient with preformed donor specific antibody before transplant and for the treatment of AMR after transplant [74].

\subsection{Eculizumab}

Eculizumab is a humanized antibody against complement C5. It inhibits the cleavage of C5 into C5a and C5b, therefore preventing formation of membrane attach complex C5b-9. Eculizumab is approved for paroxysmal nocturnal hemoglobinuria and atypical hemolytic uremia syndrome. It has been reported in treating AMR, especially the severe ones refractory to plasmapheresis and IVIG based conventional therapy [75].

\section{Considerations in Choosing a Maintenance Regimen}

There are several important factors to consider when choosing a maintenance immunosuppressive regimen for a particular patient. The patient factor includes the immunologic risk, clinical characteristics and comorbidities. The medication factor may include the drug efficacy, specific side effect and financial cost. The ideal protocol should not only effectively prevent graft rejection (both acute and chronic), but also be affordable and tolerable, which can collectively provide better quality of life as well as superior graft and patient survival. In general, the risk for acute rejection is highest in the first several months after transplantation, while the risk of serious infection and malignancy as well as other adverse effects correlate with the total amount of immunosuppression. Therefore, the immunosuppression is usually tapered slowly to a maintenance level by 6 to 12 months after transplant in absence of rejection episode.

Steroid minimization (steroid-withdrawal or steroidfree) protocols have been tried as a strategy to avoid its adverse effects. The FREEDOM trial included three groups: steroid-free, steroid-withdrawal (after 7 days) and standard-steroids (tapering to 5 to $10 \mathrm{mg}$ /day by 3 months). All groups received basiliximab induction, entericcoated MFA and cyclosporine maintenance. At 1 year, acute rejection rates were significantly higher in both steroidfree (31.5\%) and steroid-withdrawal (26.1\%) groups than standard-steroids group (14.7\%). There was no difference in renal function, graft or patient survival [76]. Another trial compared long-term results of steroid withdrawal (after 7 days) with continuance of low-dose steroid. Enrolled patients received either thymoglobulin (68\%) or IL2R antibody (32\%) induction. All patients were treated with tacrolimus and MMF as the maintenance. At 5 years, early steroid withdrawal group had significant increases in both biopsy-confirmed acute rejection (18\% vs. $11 \%)$ and CAN ( $10 \%$ vs. $4 \%$ ) without significant difference in steroid-associated adverse effects [77]. Therefore, continued steroid in the maintenance protocol is generally preferred, especially in high risk groups, such as African American patients or sensitized patients. Recent studies suggest that steroid minimization might be achievable in selected low-risk patients when potent induction therapy with T-cell depleting antibody has been given and/or combination of tacrolimus and MFA is maintained [7880].

Because of the acute and chronic nephrotoxicity, CNI free or withdrawal protocols are desirable for renal graft benefit. The CAESAR study found that cyclosporine withdrawal at 4 months after transplant was associated with higher incidence of acute rejection than the group with either low-dose or standard-dose of cyclosporine. There was no difference in renal function among the 3 groups at 1 year of follow-up [81]. The SYMPHONY study compared the four regimens: standard-dose cyclosporine/MMF/steriod, daclizumab/low-dose cyclosporine/ 
MMF, daclizumab/MMF/steroid/low-dose tacrolimus, and daclizumab/MMF/steroid/sirolimus. The results clearly favored the group with daclizumab/MMF/steroid/lowdose tacrolimus. At the end of 1 year of follow-up, lowdose tacrolimus group (target trough levels of 3 to $7 \mathrm{ng} / \mathrm{ml}$ ) had the lowest rate of rejection $(12.3 \%$, about half of other groups), superior graft function and significantly better graft survival, but higher incidence of NODAT than other groups. Interestingly, low-dose cyclosporine did not have a significant impact on any outcome than standard-dose cyclosporine [82]. At 3 years, low-dose tacrolimus group continued to provide the best results with the highest renal function and the best graft survival rate. Other three groups had similar outcomes to each other, but inferior to the low-dose tacrolimus group [83]. In another long-term study with a median follow-up of 8 years, patients were randomly assigned into tacrolimus/ MMF, tacrolimus/sirolimus or cyclosporine/sirolimus. All received IL2R antibody induction and maintenance steroid. Compared with other 2 groups, tacrolimus/MMF group had significantly lower incidence of acute rejection and better renal function at 1, 2, and 7 years. Tacrolimus/ sirolimus group had higher incidence of death with functioning graft (DWFG) than other 2 groups [84].

Trials using mTOR inhibitor sirolimus to replace MMF or CNI in maintenance have not proved to be beneficial and are frequently associated with higher incidence of rejection and inferior graft survival [62,63, 85-87]. Thus, low-dose tacrolimus combined with MFA and steroid seems to provide the most effective maintenance with good outcomes. The novel costimulation blockage belatacept is designed to provide effective immunosuppression while avoiding renal toxicity and metabolic adverse effects associated with CNI. Significantly, better renal function and improved cardiovascular and metabolic profile have been demonstrated, which might be an important step towards ultimately better graft and patient survival [67-69].

\section{REFERENCES}

[1] US Department of Health and Human Services, "2011 Annual Report of the Organ Procurement and Transplantation Network and the Scientific Registry of Transplant Recipients," American Journal of Transplantation, Vol. 13, No. S1, 2013, pp. 1-36. doi:10.5500/wjt.v2.i2.19

[2] K. Chouhan and R. Zhang, "Editorial Review: Antibody Induction Therapy in Adult Kidney Transplantation: A Controversy Continues," World Journal of Transplantation, Vol. 2, No. 2, 2012, pp. 19-26.

[3] P. L. Hibberd, N. E. Tolkoff-Rubin, A. B. Cosimi, R. T. Schooley, D. Isaacson, M. Doran, A. Delvecchio, F. L. Delmonico, H. Auchincloss Jr. and R. H. Rubin, "Symptomatic Cytomegalovirus Disease in the Cytomegalovirus Antibody Seropositive Renal Transplant Recipient
Treated with OKT3,” Transplantation, Vol. 53, No. 1, 1992, pp. 68-72.

doi:10.1097/00007890-199201000-00013

[4] J. R. Thistlethwaite Jr., J. K. Stuart, J. T. Mayes, A. O. Gaber, S. Woodle, M. R. Buckingham and F. P. Stuart, "Complications and Monitoring of OKT3 Therapy," American Journal of Kidney Diseases, Vol. 11, No. 2, 1988, pp. 112-119.

[5] L. J. Swinnen, M. R. Costanzo-Nordin, S. G. Fisher, E. J. O’Sullivan, M. R. Johnson, A. L. Heroux, G. J. Dizikes, R. Pifarre and R. I. Fisher, "Increased Incidence of Lymphoproliferative Disorder after Immunosuppression with the Monoclonal Antibody OKT3 in Cardiac-Transplant Recipients," The New England Journal of Medicine, Vol. 323, No. 25, 1990, pp. 1723-1728. doi:10.1056/NEJM199012203232502

[6] D. C. Brennan, K. Flavin, J. A. Lowell, T. K. Howard, S. Shenoy, S. Burgess, S. Dolan, J. M. Kano, M. Mahon, M. A. Schnitzler, R. Woodward, W. Irish and G. G. Singer, "A Randomized, Double-Blinded Comparison of Thymoglobulin versus Atgam for Induction Immunosuppressive Therapy in Adult Renal Transplant Recipients," Transplantation, Vol. 67, No. 7, 1999, pp. 1011-1018. doi:10.1097/00007890-199904150-00013

[7] K. L. Hardinger, M. A. Schnitzler, B. Miller, J. A. Lowell, S. Shenoy, M. J. Koch, D. Enkvetchakul, C. Ceriotti and D. C. Brennan, "Five-Year Follow up of Thymoglobulin versus ATGAM Induction in Adult Renal Transplantation,” Transplantation, Vol. 78, No. 1, 2004, pp. 136-141. doi:10.1097/01.TP.0000132329.67611.3F

[8] K. L. Hardinger, S. Rhee, P. Buchanan, M. Koch, B. Miller, D. Enkvetchakul, R. Schuessler, M. A. Schnitzler and D. C. Brennan, "A Prospective, Randomized, Double-Blinded Comparison of Thymoglobulin versus Atgam for Induction Immunosuppressive Therapy: 10-Year Results,” Transplantation, Vol. 86, No. 7, 2008, pp. 947952. doi:10.1097/TP.0b013e318187bc67

[9] W. C. Goggins, M. A. Pascual, J. A. Powelson, C. Magee, N. Tolkoff-Rubin, M. L. Farrell, D. S. Ko, W. W. Williams, A. Chandraker, F. L. Delmonico, H. Auchincloss and A. B. Cosimi, "A Prospective, Randomized, Clinical Trial of Intraoperative versus Postoperative Thymoglobulin in Adult Cadaveric Renal Transplant Recipients," Transplantation, Vol. 76, No. 5, 2003, pp. 798-802. doi:10.1097/01.TP.0000081042.67285.91

[10] W. Wong, N. Agrawal, M. Pascual, D. C. Anderson, H. H. Hirsch, K. Fujimoto, F. Cardarelli, W. C. Winkelmayer, A. B. Cosimi and N. Tolkoff-Rubin, "Comparison of Two Dosages of Thymoglobulin Used as a Short-Course for Induction in Kidney Transplantation," Transplant International, Vol. 19, No. 8, 2006, pp. 629-635. doi:10.1111/j.1432-2277.2006.00270.x

[11] R. B. Stevens, D. F. Mercer, W. J. Grant, A. G. Freifeld, J. T. Lane, G. C. Groggel, T. H. Rigley, K. J. Nielsen, M. E. Henning, J. Y. Skorupa, A. J. Skorupa, K. A. Christensen, J. P. Sandoz, A. M. Kellogg, A. N. Langnas and L. E. Wrenshall, "Randomized Trial of Single-Dose versus Divided-Dose Rabbit Anti-Thymocyte Globulin Induction in Renal Transplantation: An Interim Report," Transplantation, Vol. 85, No. 10, 2008, pp. 1391-1399. 


\section{doi:10.1097/TP.0b013e3181722fad}

[12] F. Vincenti, R. Kirkman, S. Light, G. Bumgardner, M. Pescovitz, P. Halloran, J. Neylan, A. Wilkinson, H. Ekberg, R. Gaston, L. Backman and J. Burdick (Daclizumab Triple Therapy Study Group), "Interleukin-2-Receptor Blockade with Daclizumab to Prevent Acute Rejection in Renal Transplantation," The New England Journal of Medicine, Vol. 338, 1998, pp. 161-165. doi:10.1056/NEJM199801153380304

[13] B. D. Kahan, P. R. Rajagopalan and M. Hall (United States Simulect Renal Study Group), "Reduction of the Occurrence of Acute Cellular Rejection among Renal Allograft Recipients Treated with Basiliximab, a Chimeric Anti-Interleukin-2-Receptor Monoclonal Antibody," Transplantation, Vol. 67, 1999, pp. 276-284. doi:10.1097/00007890-199901270-00016

[14] J. G. Lawen, E. A. Davies, G. Mourad, F. Oppenheimer, M. G. Molina, L. Rostaing, A. H. Wilkinson, L. L. Mulloy, B. J. Bourbigot, H. Prestele, A. Korn and D. Girault, "Randomized Double-Blind Study of Immunoprophylaxis with Basiliximab, a Chimeric Anti-Interleukin-2 Receptor Monoclonal Antibody, in Combination with Mycophenolate Mofetil-Containing Triple Therapy in Renal Transplantation,” Transplantation, Vol. 75, 2003, pp. 3743. doi:10.1097/00007890-200301150-00007

[15] A. C. Webster, E. G. Playford, G. Higgins, J. R. Chapman and J. C. Craig, "Interleukin 2 Receptor Antagonists for Renal Transplant Recipients: A Meta Analysis of Randomized Trials,” Transplantation, Vol. 77, 2004, pp. 166176. doi:10.1097/01.TP.0000109643.32659.C4

[16] A. D. Kirk, D. A. Hale, S. J. Swanson and R. B. Mannon, "Autoimmune Thyroid Disease after Renal Transplantation Using Depletional Induction with Alemtuzumab," American Journal of Transplantation, Vol. 6, No. 5, 2006, pp. 1084-1085. doi:10.1111/j.1600-6143.2006.01258.x

[17] J. Pascual, J. D. Mezrich, A. Djamali, G. Leverson, L. T. Chin, J. Torrealba, D. Bloom, B. Voss, B. N. Becker, S. J. Knechtle, H. W. Sollinger, J. D. Pirsch and M. D. Samaniego, "Alemtuzumab Induction and Recurrence of Glomerular Disease after Kidney Transplantation,” Transplantation, Vol. 83, No. 11, 2007, pp. 1429-1434. doi:10.1097/01.tp.0000264554.39645.74

[18] M. J. Hanaway, E. Steve Woodle, S. Mulgaonkar, V. Ram Peddi, D. B. Kaufman, M. Roy First, R. Croy and J. Holman, (for the INTAC Study Group), “Alemtuzumab Induction in Renal Transplantation,” The New England Journal of Medicine, Vol. 364, No. 12, 2011, pp. 19091919.

[19] H. P. Tan, J. Donaldson, A. Basu, M. Unruh, P. Randhawa, V. Sharma, C. Morgan, J. McCauley, C. Wu, N. Shah, A. Zeevi and R. Shapiro, "Two Hundred Living Donor Kidney Transplantations under Alemtuzumab Induction and Tacrolimus Monotherapy: 3-Year FollowUp,” American Journal of Transplantation, Vol. 9, No. 2, 2009, pp. 355-366. doi:10.1111/j.1600-6143.2008.02492.x

[20] D. B. Kaufman, J. R. Leventhal, D. Axelrod, L. G. Gallon, M. A. Parker and F. P. Stuart, "Alemtuzumab Induction and Prednisone-Free Maintenance Immunotherapy in
Kidney Transplantation: Comparison with Basiliximab Induction-Long-Term Results," American Journal of Transplantation, Vol. 5, No. 10, 2005, pp. 2539-2548. doi:10.1111/j.1600-6143.2005.01067.x

[21] S. M. Flechner, P. J. Friend, J. Brockmann, H. R. Ismail, M. Zilvetti, D. Goldfarb, C. Modlin, B. Mastroianni, K. Savas, A. Devaney, M. Simmonds and D. J. Cook, "Alemtuzumab Induction and Sirolimus plus Mycophenolate Mofetil Maintenance for CNI and Steroid-Free Kidney Transplant Immunosuppression," American Journal of Transplantation, Vol. 5, 2005, pp. 3009-3014. doi:10.1111/j.1600-6143.2005.01123.x

[22] A. A. Vo, M. Lukovsky, M. Toyoda, J. Wang, N. L. Reinsmoen, C. H. Lai, A. Peng, R. Villicana and S. C. Jordan, "Rituximab and Intravenous Immune Globulin for Desensitization during Renal Transplantation," The New England Journal of Medicine, Vol. 359, No. 3, 2008, pp. 242-251. doi:10.1056/NEJMoa0707894

[23] W. R. Mulley, F. J. Hudson, B. D. Tait, A. M. Skene, J. P. Dowling, P. G. Kerr, et al., "A Single Low-Fixed Dose of Rituximab to Salvage Renal Transplants from Refractory Antibody-Mediated Rejection,” Transplantation, Vol. 87, No. 2, 2009, pp. 286-289.

doi:10.1097/TP.0b013e31819389cc

[24] Kidney Disease: Improving Global Outcomes (KDIGO) Transplant Work Group, "KDIGO Clinical Practice Guideline for the Care of Kidney Transplant Recipients," American Journal of Transplantation, Vol. 9, Suppl. 3, 2009, pp. S1-155. doi:10.1111/j.1600-6143.2009.02834.X

[25] R. M. Jindal, N. P. Das, R. T. Neff, F. P. Hurst, E. M. Falta, E. A. Elster and K. C. Abbott, "Outcomes in African-Americans vs. Caucasians Using Thymoglobulin or Interleukin-2 Inhibitor Induction: Analysis of USRD Database," American Journal of Nephrology, Vol. 29, 2009, pp. 501-508. doi:10.1159/000182816

[26] D. C. Brennan, J. A. Daller, K. D. Lake, D. Cibrik and D. Del Castillo, "Rabbit Antithymocyte Globulin versus Basiliximab in Renal Transplantation,” The New England Journal of Medicine, Vol. 355, 2006, pp. 1967-1977. doi:10.1056/NEJMoa060068

[27] V. Patlolla, X. Zhong, G. W. Reed and D. A. Mandelbrot, "Efficacy of Anti IL2 Receptor Antibodies Compared to No Induction and to Antilymphocyte Antibodies in Renal Transplantation," American Journal of Transplantation, Vol. 7, 2007, pp. 832-1842. doi:10.1111/j.1600-6143.2007.01860.x

[28] F. L. Luan, D. E. Schaubel, H. Zhang, X. Jia, S. J. Pelletier, F. K. Port, J. C. Magee and R. S. Sung, "Impact of Immunosuppressive Regimen on Survival of Kidney Transplant Recipients with Hepatitis C," Transplantation, Vol. 85, No. 11, 2008, pp. 1601-1606. doi:10.1097/TP.0b013e3181722f3a

[29] P. G. Stock, B. Barin, B. Murphy, D. Hanto, J. M. Diego, J. Light, C. Davis, E. Blumberg, D. Simon, A. Subramanian, J. M. Millis, G. M. Lyon, K. Brayman, D. Slakey, R. Shapiro, J. Melancon, J. M. Jacobson, V. Stosor, J. L. Olson, D. M. Stablein and M. E. Roland, "Outcomes of Kidney Transplantation in HIV-Infected Recipients,” The New England Journal of Medicine, Vol. 363, No. 21, 
2010, pp. 2004-2014. doi:10.1056/NEJMoa1001197

[30] S. J. Patel, R. J. Knight, W. N. Suki, A. Abdellatif, B. T. Duhart Jr., A. G. Krauss, S. Mannan, N. Nezakatgoo and A. Osama Gaber, "Rabbit Antithymocyte Induction and Dosing in Deceased Donor Renal Transplant Recipients over 60 yr of Age," Clinical Transplantation, Vol. 25, No. 3, 2011, E250-E256. doi:10.1111/j.1399-0012.2010.01393.x

[31] R. L. Morton, K. Howard, A. C. Webster, G. Wong and J. C. Craig, "The Cost Effectiveness of Induction Immunosuppression in Kidney Transplantation,” Nephrology Dialysis Transplantation, Vol. 24, No. 7, 2009, pp. 22582269. doi:10.1093/ndt/gfp174

[32] P. F. Halloran, "Immunosuppressive Drugs for Kidney Transplantation,” The New England Journal of Medicine, Vol. 351, No. 26, 2004, pp. 2715-2729. doi:10.1056/NEJMra033540

[33] A. B. Leichtman, "Balancing Efficacy and Toxicity in Kidney-Transplant Immunosuppression," The New England Journal of Medicine, Vol. 357, No. 25, 2007, pp. 2625-2627. doi:10.1056/NEJMe078181

[34] D. E. Hricik, W. Y. Almawi and T. B. Strom, "Trends in the Use of Glucocorticoids in Renal Transplantation," Transplantation, Vol. 57, No. 7, 1994, pp. 979-989.

[35] K. Midtvedt, J. Hjelmesaeth, A. Hartmann, K. Lund, D. Paulsen, T. Egeland, et al., "Insulin Resistance after Renal Transplantation: The Effect of Steroid Dose Reduction and Withdrawal," Journal of the American Society of Nephrology, Vol. 15, No. 12, 2004, pp. 3233-3239. doi:10.1097/01.ASN.0000145435.80005.1E

[36] The Canadian Multicentre Transplant Study Group, “A Randomized Clinical Trial of Cyclosporine in Cadaveric Renal Transplantation. Analysis at Three Years," The New England Journal of Medicine, Vol. 314, No. 19, pp. 1219-1225.

[37] E. A. Mueller, J. M. Kovarik, J. B. van Bree, A. E. Lison and K. Kutz, "Pharmacokinetics and Tolerability of a Microemulsion Formulation of Cyclosporine in Renal Allograft Recipients-A Concentration-Controlled Comparison with the Commercial Formulation," Transplantation, Vol. 57, No. 8, 1994, pp. 1178-1182. doi:10.1097/00007890-199404270-00007

[38] M. D. Pescovitz, G. Barone, M. G. Choc Jr., D. E. Hricik, D. S. Hwang, J. H. Jin, et al., "Safety and Tolerability of Cyclosporine Microemulsion versus Cyclosporine: TwoYear Data in Primary Renal Allograft Recipients: A Report of the Neoral Study Group," Transplantation, Vol. 63, No. 5, 1997, pp. 778-780. doi:10.1097/00007890-199703150-00027

[39] C. Ponticelli, L. Minetti, F. Q. Di Palo, A. Vegeto, L. Belli, G. Corbetta, et al., "The Milan Clinical Trial with Cyclosporine in Cadaveric Renal Transplantation: A Three-Year Follow-Up,” Transplantation, Vol. 45, No. 5, 1988, pp. 908-913. doi:10.1097/00007890-198805000-00013

[40] S. R. Knight and P. J. Morris, "The Clinical Benefits of Cyclosporine C2-Level Monitoring: A Systematic Review," Transplantation, Vol. 83, No. 12, 2007, pp. 1525-1535. doi:10.1097/01.tp.0000268306.41196.2c
[41] G. A. Knoll and R. C. Bell, "Tacrolimus versus Cyclosporin for Immunosuppression in Renal Transplantation: Meta-Analysis of Randomised Trials,” British Medical Journal, Vol. 318, No. 7191, 1999, pp. 1104-1107. doi:10.1136/bmj.318.7191.1104

[42] K. L. Hardinger, D. L. Bohl, M. A. Schnitzler, M. Lockwood, G. A. Storch and D. C. Brennan, “A Randomized, Prospective, Pharmacoeconomic Trial of Tacrolimus versus Cyclosporine in Combination with Thymoglobulin in Renal Transplant Recipients,” Transplantation, Vol. 80, No. 1, 2005, pp. 41-46. doi:10.1097/01.TP.0000162980.68628.5A

[43] R. Margreiter (European Tacrolimus vs Ciclosporin Microemulsion Renal Transplantation Study Group), "Efficacy and Safety of Tacrolimus Compared with Ciclosporin Microemulsion in Renal Transplantation: A Randomised Multicentre Study,” Lancet, Vol. 359, No. 9308, 2002, pp. 741-746. doi:10.1016/S0140-6736(02)07875-3

[44] A. C. Webster, R. C. Woodroffe, R. S. Taylor, J. R. Chapman and J. C. Craig, "Tacrolimus versus Ciclosporin as Primary Immunosuppression for Kidney Transplant Recipients: Meta-Analysis and Meta-Regression of Randomised Trial Data,” British Medical Journal, Vol. 331, No. 7520, 2005, p. 810. doi:10.1136/bmj.38569.471007.AE

[45] B. K. Krämer, D. Del Castillo, R. Margreiter, H. Sperschneider, C. J. Olbricht, J. Ortuño, U. Sester, U. Kunzendorf, K. H. Dietl, V. Bonomini, P. Rigotti, C. Ronco, J. M. Tabernero, M. Rivero, B. Banas, F. Mühlbacher, M. Arias and G. Montagnino, "Efficacy and Safety of Tacrolimus Compared with Ciclosporin A in Renal Transplantation: Three-Year Observational Results," Nephrol Dial Transplant, Vol. 23, No. 7, 2008, pp. 2386-2392. doi:10.1093/ndt/gfn004

[46] H. T. Silva Jr., H. C. Yang, M. Abouljoud, P. C. Kuo, K. Wisemandle, P. Bhattacharya, et al., "One-Year Results with Extended-Release Tacrolimus/MMF, Tarolimus/ MMF and Cyclosporine/MMF in De Novo Kidney Transplant Recipients," American Journal of Transplan- tation, Vol. 7, No. 3, 2007, pp. 595-608. doi:10.1111/j.1600-6143.2007.01661.x

[47] S. Bergan, H. E. Rugstad, O. Bentdal, G. Sodal, A. Hartmann, T. Leivestad, et al., "Monitored High-Dose Azathioprine Treatment Reduces Acute Rejection Episodes after Renal Transplantation,” Transplantation, Vol. 66, No. 3, 1998, pp. 334-339. doi:10.1097/00007890-199808150-00010

[48] G. Remuzzi, P. Cravedi, M. Costantini, M. Lesti, M. Ganeva, G. Gherardi, et al., "Mycophenolate Mofetil versus Azathioprine for Prevention of Chronic Allograft Dysfunction in Renal Transplantation: The MYSS Follow-Up Randomized, Controlled Clinical Trial,” Journal of American Society of Nephrology, Vol. 18, No. 6, 2007, pp. 1973-1985. doi:10.1681/ASN.2006101153

[49] B. D. Kahan (The Rapamune US Study Group), "Efficacy of Sirolimus Compared with Azathioprine for Reduction of Acute Renal Allograft Rejection: A Randomised Multicentre Study," Lancet, Vol. 356, No. 9225, 2000, pp. 194-202. doi:10.1016/S0140-6736(00)02480-6 
[50] H. U. Meier-Kriesche, B. J. Steffen, A. M. Hochberg, R. D. Gordon, M. N. Liebman, J. A. Morris, et al., "Long-Term Use of Mycophenolate Mofetil Is Associated with a Reduction in the Incidence and Risk of Late Rejection," American Journal of Transplantation, Vol. 3, No. 1, 2003, pp. 68-73. doi:10.1034/j.1600-6143.2003.30112.x

[51] J. F. Neylan (US Renal Transplant Mycophenolate Mofetil Study Group), "Immunosuppressive Therapy in High-Risk Transplant Patients: Dose-Dependent Efficacy of Mycophenolate Mofetil in African-American Renal Allograft Recipients,” Transplantation, Vol. 64, No. 9, 1997, pp. 1277-1282. doi:10.1097/00007890-199711150-00008

[52] H. W. Sollinger (US Renal Transplant Mycophenolate Mofetil Study Group), "Mycophenolate Mofetil for the Prevention of Acute Rejection in Primary Cadaveric Renal Allograft Recipients,” Transplantation, Vol. 60, No. 3, 1995, pp. 225-232. doi:10.1097/00007890-199508000-00003

[53] The Tricontinental Mycophenolate Mofetil Renal Transplantation Study Group, “A Blinded, Randomized Clinical Trial of Mycophenolate Mofetil for the Prevention of Acute Rejection in Cadaveric Renal Transplantation,” Transplantation, Vol. 61, No. 7, 1996, pp. 1029-1037. doi:10.1097/00007890-199604150-00008

[54] S. Kofler, N. Shvets, A. K. Bigdeli, M. A. Konig, P. Kaczmarek, M. A. Deutsch, et al., "Proton Pump Inhibitors Reduce Mycophenolate Exposure in Heart Transplant Recipients-A Prospective Case-Controlled Study,” American Journal of Transplantation, Vol. 9, No. 7, 2009, pp. 1650-1656. doi:10.1111/j.1600-6143.2009.02682.x

[55] B. A. Kiberd, M. Wrobel, R. Dandavino, P. Keown and S. Gourishankar, "The Role of Proton Pump Inhibitors on Early Mycophenolic Acid Exposure in Kidney Transplantation: Evidence from the CLEAR Study," Therapeutic Drug Monitoring, Vol. 33, No. 1, 2011, pp. 120-123. doi:10.1097/FTD.0b013e318206a1b1

[56] P. Bolin, B. Tanriover, G. B. Zibari, M. L. Lynn, J. D. Pirsch, L. Chan, et al., "Improvement in 3-Month Patient-Reported Gastrointestinal Symptoms after Conversion from Mycophenolate Mofetil to Enteric-Coated Mycophenolate Sodium in Renal Transplant Patients," Transplantation, Vol. 84, No. 11, 2007, pp. 1443-1451. doi:10.1097/01.tp.0000290678.06523.95

[57] S. Bunnapradist, K. L. Lentine, T. E. Burroughs, B. W. Pinsky, K. L. Hardinger, D. C. Brennan, et al., "Mycophenolate Mofetil Dose Reductions and Discontinuations after Gastrointestinal Complications Are Associated with Renal Transplant Graft Failure,” Transplantation, Vol. 82, No. 1, 2006, pp. 102-107. doi:10.1097/01.tp.0000225760.09969.1f

[58] A. J. Langone, L. Chan, P. Bolin and M. Cooper, "Enteric-Coated Mycophenolate Sodium versus Mycophenolate Mofetil in Renal Transplant Recipients Experiencing Gastrointestinal Intolerance: A Multicenter, Double-Blind, Randomized Study," Transplantation, 2011 Vol. 91, No. 4, pp. 470-478.

[59] A. S. Chong, H. Zeng, D. A. Knight, J. Shen, G. T. Meister, J. W. Williams, et al., "Concurrent Antiviral and
Immunosuppressive Activities of Leflunomide in Vivo," American Journal of Transplantation, Vol. 6, No. 1, 2006, pp. 69-75. doi:10.1111/j.1600-6143.2005.01152.x

[60] M. A. Josephson, D. Gillen, B. Javaid, P. Kadambi, S. Meehan, P. Foster, et al., "Treatment of Renal Allograft Polyoma BK Virus Infection with Leflunomide,” Transplantation, Vol. 81, No. 5, 2006, pp. 704-710. doi:10.1097/01.tp.0000181149.76113.50

[61] C. G. Groth, L. Backman, J. M. Morales, R. Calne, H. Kreis, P. Lang, et al. ( Sirolimus European Renal Transplant Study Group), “Sirolimus (Rapamycin)-Based Therapy in Human Renal Transplantation: Similar Efficacy and Different Toxicity Compared with Cyclosporine," Transplantation, Vol. 67, No. 7, 1999, pp. 1036-1042. doi:10.1097/00007890-199904150-00017

[62] H. U. Meier-Kriesche, J. D. Schold, T. R. Srinivas, R. J. Howard, S. Fujita and B. Kaplan, "Sirolimus in Combination with Tacrolimus Is Associated with Worse Renal Allograft Survival Compared to Mycophenolate Mofetil Combined with Tacrolimus," American Journal of Transplantation, Vol. 5, No. 9, 2005, pp. 2273-2280. doi:10.1111/j.1600-6143.2005.01019.x

[63] H. U. Meier-Kriesche, B. J. Steffen, A. H. Chu, J. J. Loveland, R. D. Gordon, J. A. Morris, et al., "Sirolimus with Neoral versus Mycophenolate Mofetil with Neoral Is Associated with Decreased Renal Allograft Survival," American Journal of Transplantation, Vol. 4, No. 12, 2004, pp. 2058-2066.

doi:10.1111/j.1600-6143.2004.00624.x

[64] K. Budde, T. Becker, W. Arns, C. Sommerer, P. Reinke, U. Eisenberger, et al., "Everolimus-Based, CalcineurinInhibitor-Free Regimen in Recipients of De-Novo Kidney Transplants: An Open-Label, Randomised, Controlled Trial,” Lancet, Vol. 377, No. 9768, 2011, pp. 837-847. doi:10.1016/S0140-6736(10)62318-5

[65] G. Ciancio, G. W. Burke, J. J. Gaynor, P. Ruiz, D. Roth, W. Kupin, et al., "A Randomized Long-Term Trial of Tacrolimus/Sirolimus versus Tacrolimums/Mycophenolate versus Cyclosporine/Sirolimus in Renal Transplantation: Three-Year Analysis,” Transplantation, Vol. 81, No. 6, 2006, pp. 845-852. doi:10.1097/01.tp.0000203894.53714.27

[66] F. Vincenti, C. Larsen, A. Durrbach, T. Wekerle, B. Nashan, G. Blancho, et al., "Costimulation Blockade with Belatacept in Renal Transplantation,” The New England Journal of Medicine, Vol. 353, No. 8, 2005, pp. 770-781. doi:10.1056/NEJMoa050085

[67] A. Durrbach, J. M. Pestana, T. Pearson, F. Vincenti, V. D. Garcia, J. Campistol, et al., "A Phase III Study of Belatacept versus Cyclosporine in Kidney Transplants from Extended Criteria Donors (BENEFIT-EXT Study)," American Journal of Transplantation, Vol. 10, No. 3, 2010, pp. 547-557. doi:10.1111/j.1600-6143.2010.03016.x

[68] F. Vincenti, B. Charpentier, Y. Vanrenterghem, L. Rostaing, B. Bresnahan, P. Darji, et al., "A Phase III Study of Belatacept-Based Immunosuppression Regimens versus Cyclosporine in Renal Transplant Recipients (BENEFIT Study)," American Journal of Transplantation, Vol. 
10, No. 3, 2010, pp. 535-546. doi:10.1111/j.1600-6143.2009.03005.X

[69] F. Vincenti, G. Blancho, A. Durrbach, P. Friend, J. Grinyo, P. F. Halloran, et al., "Five-Year Safety and Efficacy of Belatacept in Renal Transplantation,” Journal of American Society of Nephrology, Vol. 21, No. 9, 2010, pp. 1587-1596. doi:10.1681/ASN.2009111109

[70] M. Toyoda, A. Pao, A. Petrosian and S. C. Jordan, "Pooled Human Gammaglobulin Modulates Surface Molecule Expression and Induces Apoptosis in Human B Cells," American Journal of Transplantation, Vol. 3, No. 2, 2003, pp. 156-166. doi:10.1034/j.1600-6143.2003.00011.X

[71] P. P. Luke, V. P. Scantlebury, M. L. Jordan, C. A. Vivas, T. R. Hakala, A. Jain, et al., "Reversal of Steroid- and Anti-Lymphocyte Antibody-Resistant Rejection Using Intravenous Immunoglobulin (Ivig) in Renal Transplant Recipients," Transplantation, Vol. 72, No. 3, 2001, pp. 419-422. doi:10.1097/00007890-200108150-00010

[72] P. N. Rocha, D. W. Butterly, A. Greenberg, D. N. Reddan, J. Tuttle-Newhall, B. H. Collins, et al., "Beneficial Effect of Plasmapheresis and Intravenous Immunoglobulin on Renal Allograft Survival of Patients with Acute Humoral Rejection,” Transplantation, Vol. 75, No. 9, 2003, pp. 1490-1495. doi:10.1097/01.TP.0000060252.57111.AC

[73] D. H. Casadei, M. del C Rial, G. Opelz, J. C. Golberg, J. A. Argento, G. Greco, et al., "A Randomized and Prospective Study Comparing Treatment with High-Dose Intravenous Immunoglobulin with Monoclonal Antibodies for Rescue of Kidney Grafts with Steroid-Resistant Rejection,” Transplantation, Vol. 71, No. 1, 2001, pp. 53-58. doi:10.1097/00007890-200101150-00009

[74] M. J. Everly, J. J. Everly, B. Susskind, P. Brailey, L. J. Arend, R. R. Alloway, et al., "Bortezomib Provides Effective Therapy for Antibody- and Cell-Mediated Acute Rejection," Transplantation, Vol. 86, No. 12, 2008, pp. 1754-1761. doi:10.1097/TP.0b013e318190af83

[75] J. E. Locke, C. M. Magro, A. L. Singer, D. L. Segev, M. Haas, A. T. Hillel, et al., "The Use of Antibody to Complement Protein C5 for Salvage Treatment of Severe Antibody-Mediated Rejection,” American Journal of Transplantation, Vol. 9, No. 1, 2009, pp. 231-235. doi:10.1111/j.1600-6143.2008.02451.X

[76] F. Vincenti, F. P. Schena, S. Paraskevas, I. A. Hauser, R. G. Walker, J. Grinyo, et al., "A Randomized, Multicenter Study of Steroid Avoidance, Early Steroid Withdrawal or Standard Steroid Therapy in Kidney Transplant Recipients," American Journal of Transplantation, Vol. 8, No. 2, 2008, pp. 307-316. doi:10.1111/j.1600-6143.2007.02057.x

[77] E. S. Woodle, M. R. First, J. Pirsch, F. Shihab, A. O. Gaber, P. Van Veldhuisen, et al., "A Prospective, Randomized, Double-Blind, Placebo-Controlled Multicenter trial Comparing Early (7 Day) Corticosteroid Cessation versus Long-Term, Low-Dose Corticosteroid Therapy," Annals of Surgery, Vol. 248, No. 4, 2008, pp. 564-577.

[78] M. J. Hanaway, E. S. Woodle, S. Mulgaonkar, V. R. Peddi, D. B. Kaufman, M. R. First, R. Croy, J. Holman (INTAC Study Group), “Alemtuzumab Induction in Re- nal Transplantation," The New England Journal of Medicine, Vol. 364, No. 20, 2011, pp. 1909-1919.

doi:10.1056/NEJMoa1009546

[79] D, Chhabra, A. I. Skaro, J. R. Leventhal, P. Dalal, G. Shah, E. Wang, et al., "Long-Term Kidney Allograft Function and Survival in Prednisone-Free Regimens: Tacrolimus/Mycophenolate Mofetil versus Tacrolimus/ Sirolimus," Clinical Journal of the American Society of Nephrology, Vol. 7, No. 3, 2012, pp. 504-512. doi:10.2215/CJN.06940711

[80] R. L. Heilman, K. Younan, H. M. Wadei, M. L. Mai, K. S. Reddy, H. A. Chakkera, et al., "Results of a Prospective Randomized Trial of Sirolimus Conversion in Kidney Transplant Recipients on Early Corticosteroid Withdrawal," Transplantation, Vol. 92, No. 7, 2011, pp. 767-773. doi:10.1097/TP.0b013e31822805d7

[81] H. Ekberg, J. Grinyó, B. Nashan, Y. Vanrenterghem, F. Vincenti, A. Voulgari, M. Truman, C. Nasmyth-Miller and M. Rashford, "Cyclosporine Sparing with Mycophenolate Mofetil, Daclizumab and Corticosteroids in Renal Allograft Recipients: The CAESAR Study," American Journal of Transplantation, Vol. 7, No. 3, 2007, pp. 560-70. doi:10.1111/j.1600-6143.2006.01645.x

[82] H. Ekberg, H. Tedesco-Silva, A. Demirbas, S. Vitko, B. Nashan, A. Gurkan, et al., "Reduced Exposure to Calcineurin Inhibitors in Renal Transplantation," The New England Journal of Medicine, Vol. 357, No. 25, 2007, pp. 2562-2575. doi:10.1056/NEJMoa067411

[83] H. Ekberg, C. Bernasconi, H. Tedesco-Silva, S. Vítko, C. Hugo, A. Demirbas, R. R. Acevedo, J. Grinyó, U. Frei, Y. Vanrenterghem, P. Daloze and P. Halloran, "Calcineurin Inhibitor Minimization in the Symphony Study: Observational Results 3 Years after Transplantation,” American Journal of Transplantation, Vol. 9, No. 8, 2009, pp. 1876-1885. doi:10.1111/j.1600-6143.2009.02726.x

[84] G. Guerra, G. Ciancio, J. J. Gaynor, A. Zarak, R. Brown, L. Hanson, et al., "Randomized Trial of Immunosuppressive Regimens in Renal Transplantation," Journal of American Society of Nephrology, Vol. 22, No. 9, 2011, pp. 1758-1768. doi:10.1681/ASN.2011010006

[85] T. R. Srinivas, J. D. Schold, G. Guerra, A. Eagan, C. M. Bucci and H. U. Meier-Kriesche, "Mycophenolate Mofetil/Sirolimus Compared to Other Common Immunosuppressive Regimens in Kidney Transplantation," American Journal of Transplantation, Vol. 7, No. 3, 2007, pp. 586-594. doi:10.1111/j.1600-6143.2006.01658.x

[86] M. R. Weir, S. Mulgaonkar, L. Chan, H. Shidban, T. H. Waid, D. Preston, et al., "Mycophenolate Mofetil-Based Immunosuppression with Sirolimus in Renal Transplation: A Randomized, Controlled Spare-the-Nephron Trial," Kidney International, Vol. 79, No. 8, 2011, pp. 897-907.

[87] S. M. Flechner, M. Glyda, S. Cockfield, J. Grinyo, C. Legendre, G. Russ, et al., "The ORION Study: Comparison of Two Sirolimus-Based Regimens versus Tacrolimus and Mycophenolate Mofetil in Renal Allograft Recipients," American Journal of Transplantation, Vol. 11, No. 8, 2011, pp. 1633-1644. doi:10.1111/j.1600-6143.2011.03573.x 